\title{
Assessment of the Safety Level of Concrete Slabs during Fire
}

\author{
RUBEN VAN COILE, EMMANUEL ANNEREL, ROBBY CASPEELE, and LUC TAERWE \\ Ghent University, Faculty of Engineering \\ Department of Structural Engineering \\ Magnel Laboratory for Concrete Research \\ Technologiepark-Zwijnaarde 904, 9052 Ghent, Belgium
}

\begin{abstract}
During the last decades research has provided many new insights in the structural behavior of concrete structures subjected to fire. However, most studies and also the semi-probabilistic design methods in the Eurocode EN 1992-1-2 focus on the maximum time of fire resistance, without mentioning the impact of fire on the safety level of the structure. In order to assess the effect of fire on the safety level of concrete slabs, a full-probabilistic model is developed, using Monte Carlo simulations for modeling the uncertainty regarding the bending moment capacity. Results indicate that the calculated safety level is highly sensitive to the uncertainty of temperature effects on material properties. Furthermore, it is shown that the safety level at the fire resistance time is not the same for all the design approaches mentioned in EN 1992-1-2. Also, a generalized target value for the safety index $\beta$ during fire is proposed, which allows for an objective comparison of the fire resistance time for different design alternatives.
\end{abstract}

KEYWORDS: concrete, structural response, risk, Monte Carlo.

\section{NOMENCLATURE LISTING}

\begin{tabular}{llll}
$a$ & distance from reinforcement axis to & \multicolumn{2}{l}{ Greek } \\
& exposed concrete surface $(\mathrm{mm})$ & $\alpha_{R}$ & sensitivity factor $(-)$ \\
$A_{s}$ & steel section $\left(\mathrm{mm}^{2}\right)$ & $\beta^{*}$ & reliability index $(-)$ \\
$c$ & concrete cover $(\mathrm{mm})$ & $\delta$ & coefficient of variation $(-)$ \\
$c_{n o m i n a l}$ & nominal value of c $(\mathrm{mm})$ & $\theta$ & temperature $\left({ }^{\circ} \mathrm{C}\right)$ \\
$E_{c}$ & concrete modulus of elasticity $(\mathrm{MPa})$ & $\varepsilon$ & material strain $(-)$ \\
$E_{s}$ & steel modulus of elasticity $(\mathrm{MPa})$ & $\eta_{f c}$ & reduction coefficient $f_{c}(\theta) / f_{c}\left(20^{\circ} \mathrm{C}\right)(-)$ \\
$f_{c}$ & concrete compressive strength $(\mathrm{MPa})$ & $\eta_{f y}$ & reduction coefficient $f_{y}(\theta) / f_{y}\left(20^{\circ} \mathrm{C}\right)(-)$ \\
$f_{y}$ & yield strength reinforcement $(\mathrm{MPa})$ & $\chi$ & model uncertainty $(-)$ \\
$f_{s p}$ & proportionality limit steel $(\mathrm{MPa})$ & $\mu$ & mean \\
$h$ & total depth of slab $(\mathrm{mm})$ & $\sigma$ & standard deviation \\
$M_{E}$ & load induced bending moment $(\mathrm{kN} \cdot \mathrm{m})$ & $\Phi$ & normalized cumulative normal \\
$M_{E d}$ & design value of $M_{E}(\mathrm{kN} \cdot \mathrm{m})$ & \multicolumn{2}{c}{ distribution } \\
$M_{R}$ & bending moment capacity $(\mathrm{kN} \cdot \mathrm{m})$ & symbols \\
$M_{R d}$ & design value of $M_{R}(\mathrm{kN} \cdot \mathrm{m})$ & $\varnothing$ & reinforcement bar diameter $(\mathrm{mm})$ \\
$M_{R, f i t}$ & M during fire, at time $t(\mathrm{kN} \cdot \mathrm{m})$ & subscripts \\
$P_{f}$ & probability of failure $(-)$ & $f i \quad$ during fire \\
$R$ & fire resistance $(\min )$ & $t \quad$ at time $t$ \\
$t$ & time (min) & $i$ & at discretization point ' $i$
\end{tabular}

\section{INTRODUCTION}

Fire safety of concrete structures is a topic of great importance to both the legislators and the general public. Though total failure of a structure due to fire exposure may be rather exceptional, recent examples like the partial collapse of the Windsor Tower in Madrid (2005) and the collapse of the Architecture faculty of the TU Delft in the Netherlands (2008) illustrate the devastating effect of fires. Especially the risk of progressive collapse of multiple storey constructions poses a significant threat. Considering the increasing number of dense high-rise districts in almost all of the world's main cities, and both the economic and social consequences, evaluation of fire resistance of structures is an important research topic. 
In the European union the main directives for structural analysis are provided by the Eurocodes. Though the Eurocodes partly focus on the performance of structures exposed to fire [1,2], it is unclear which safety level corresponds to a structure at the specified fire resistance time. Analyzing this safety level is important in order to assess the probability of structural collapse and to give designers a clear view on the relative safety of different design alternatives. Furthermore, the type of probabilistic analysis proposed in this paper can also be used to calibrate partial safety factors.

\section{OBJECTIVES OF THE RESEARCH}

The main objective is to create insight in the evolution of the structural reliability and safety of concrete slabs during fire. Therefore, the effects of stochastic uncertainties with respect to variables must be included in the calculations. Due to the fact that the limit state function of the problem is not available in a closed form, classical FORM-analysis is not possible. An alternative procedure must be used. This procedure will allow for a comparison of the actual bending moment capacity to the design value of the bending moment capacity based on the semi-probabilistic methods prescribed by the Eurocodes.

Additionally, a second goal is to make a first suggestion for the target value of the reliability index $\beta$ to be used in the design and evaluation of concrete slabs subjected to fire, based on a comparison of calculation results with the design approaches of EN 1992-1-2. This target value allows for a more specific determination and comparison of the fire resistance time of different design alternatives.

\section{THE MODEL CONCEPTS}

\section{The Initial Deterministic Approach}

A simple deterministic model is developed in a spreadsheet. This model is capable of evaluating the bending moment capacity of a concrete slab during fire. Though the actual behavior is the result of physical and chemical changes [3], the effects of fire on the material properties of both concrete and reinforcing steel are evaluated solely through temperature effects. This simplification corresponds to the methodology followed in EN 1992-1-2 [1]. The temperature distribution is calculated by the finite element program Diana at discrete times $t$, with the slab exposed to the ISO 834 fire curve from the bottom side only.

For the evaluation of the temperature effect on the material properties, a discretization of the thickness $h$ of the slab in elements with height $h_{i}$ (e.g. $5 \mathrm{~mm}$ ) is necessary (Fig 1). The local strain $\varepsilon_{i}$ and temperature $\theta_{i}$ are evaluated in the center of a particular element (in the 'discretization point $i$ '). The model assumes this temperature and strain to be uniform for the entire element with height $h_{i}$. The reinforcement is implemented in the model as a single horizontal point load. The ultimate limit state is calculated based on a cracked concrete section. Further, cracks that are introduced by internal thermal restraint are not considered in this model.

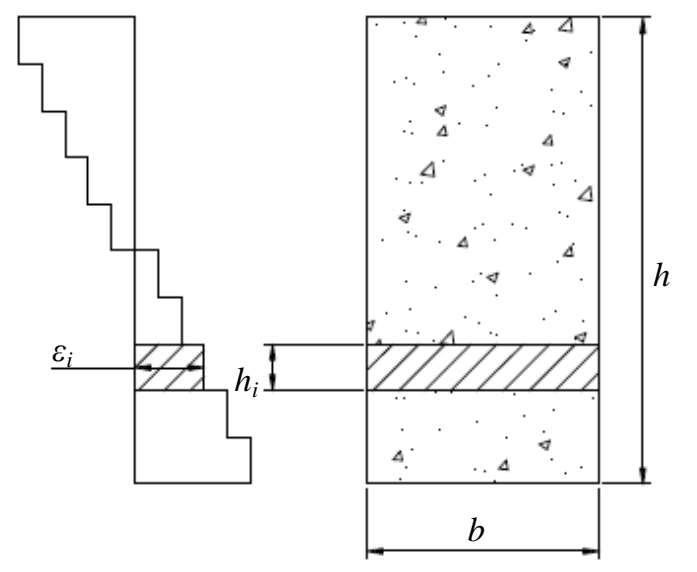

(a) (b)

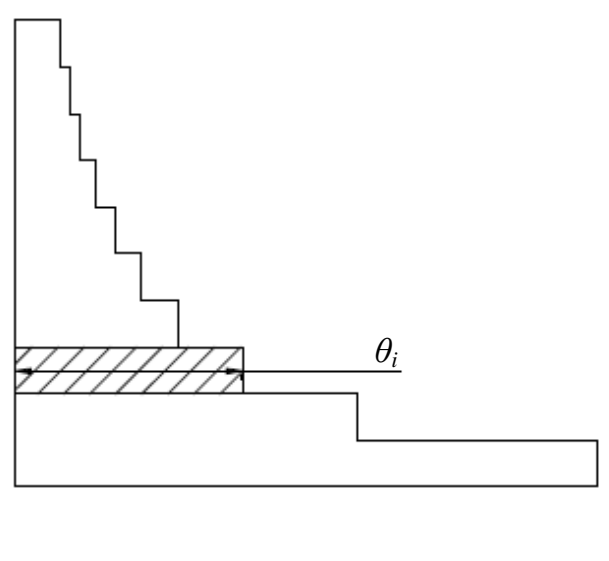

(c)

Fig. 1. Discretization of a flat slab cross section: (a) distribution of strains; (b) segment of concrete slab; (c) temperature distribution. 
At specific time intervals, the model evaluates the temperature and the corresponding mechanical properties for each $\mathrm{i}$ and calculates the ultimate bending limit state of the slab through an iterative scheme. This ultimate limit state is characterized by the Euler-Bernouilli assumption (i.e. plane sections remain plane) and the requirement that the ultimate strain of either the compressed concrete equals $3.5 \%$, the tensile steel strain equals $10 \%$, or both boundaries are reached. These assumptions are also used in the classical linear-elastic structural analysis [4].

Based on these strain assumptions and the requirement to have no resulting axial force in the ultimate bending limit state, the linear distribution of $\varepsilon$ across the depth of the concrete element can be determined. From this strain distribution the bending moment capacity of the slab $M_{R, f i, t}$ is calculated at $\mathrm{t}$ minutes of fire. The result of this deterministic calculation is multiplied with a model uncertainty factor $\chi$, in accordance with Ref. [5].

\section{Probabilistic Basic Variables and Subsequent Statistical Evaluation}

The uncertainties with respect to the basic variables are incorporated in the model through their respective probabilistic distributions as presented in Table 1 and found in Ref. [5].

Table 1. Distribution of probabilistic variables.

\begin{tabular}{|l|l|l|}
\hline \multicolumn{1}{|c|}{ Symbol } & \multicolumn{1}{c|}{ Name } & \multicolumn{1}{c|}{ Distribution } \\
\hline$h$ & thickness / height slab & normal \\
\hline$f_{c}\left(20^{\circ} \mathrm{C}\right)$ & $20^{\circ} \mathrm{C}$ concrete compressive strength & log-normal \\
\hline$f_{v}\left(20^{\circ} \mathrm{C}\right)$ & $20^{\circ} \mathrm{C}$ steel yield strength & log-normal \\
\hline$E_{c}\left(20^{\circ} \mathrm{C}\right)$ & $20^{\circ} \mathrm{C}$ concrete modulus of elasticity & log-normal \\
\hline$A_{s}$ & steel section & normal \\
\hline$c$ & concrete cover & beta [0;3 $\left.c_{\text {nominal }}\right]$ \\
\hline$\chi$ & model uncertainty & lognormal \\
\hline
\end{tabular}

In order to take the uncertainty of heating on the mechanical properties into account, a standard deviation is proposed based on laboratory tests. This standard deviation is applied on the nominal reduction of mechanical properties $f_{c}$ and $f_{y}$ as prescribed in EN 1992-1-2 [1]. Outside the European Union different nominal reduction factors are used, for example assuming the steel yield stress to reduce to 0 at $700{ }^{\circ} \mathrm{C}$. While the difference beyond $700{ }^{\circ} \mathrm{C}$ can have a significant effect, it is of less importance with respect to the modeling that is described in this paper, since the exposure is modeled for only $240 \mathrm{~min}$. At $240 \mathrm{~min}$ of exposure the rebar temperature is calculated to reach only $650{ }^{\circ} \mathrm{C}$ (Fig. 2).

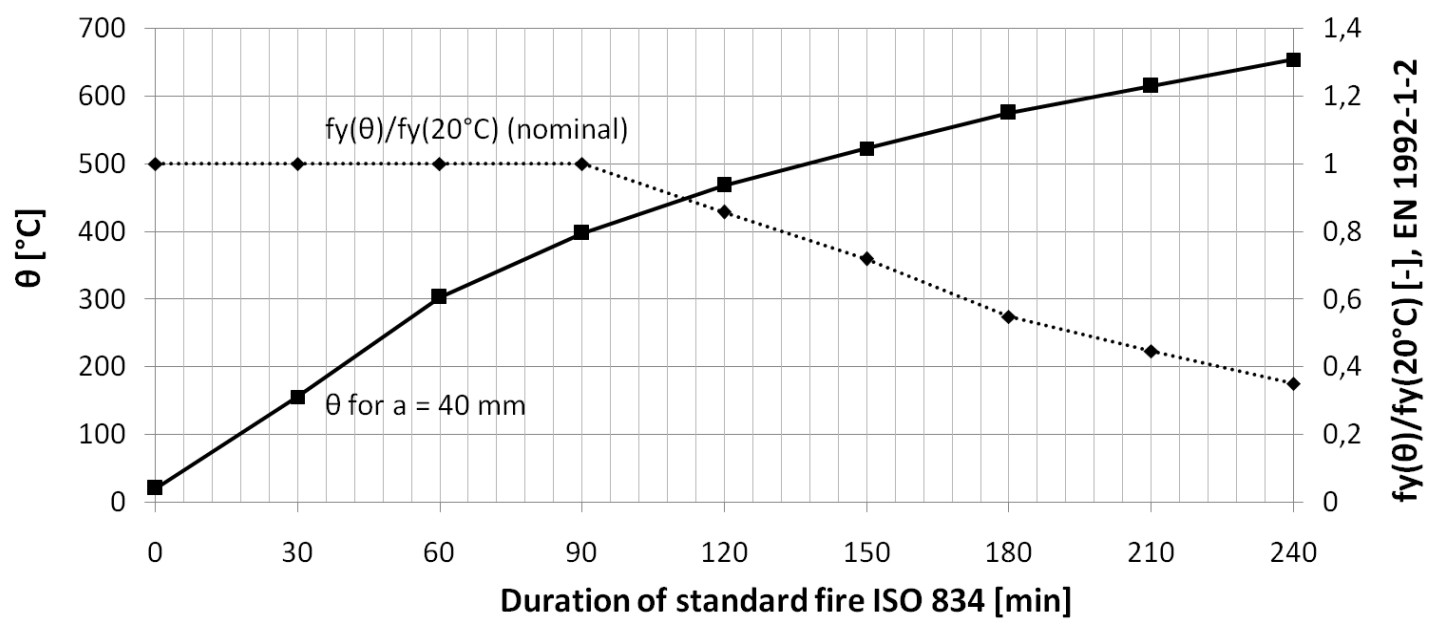

Fig. 2. Rebar temperature and nominal reduction factor as a function of exposure time.

For the compressive concrete strength, the standard deviation is assumed to be 0 at $20{ }^{\circ} \mathrm{C}$ and 0.045 at $700{ }^{\circ} \mathrm{C}$. Interpolation is used for intermediate values. For the mechanical steel properties, a similar 
assumption is made, with a standard deviation of 0.065 at $600{ }^{\circ} \mathrm{C}$. These temperature effects are modeled by a normal distribution. For example, at $500^{\circ} \mathrm{C}$ the reduction factor for $f_{y}$ is described by a mean of 0.78 and a standard deviation of 0.052 .

Figure 3 shows the $5 \%, 50 \%$ and $95 \%$ fractiles of the reduction variable $f_{y}(\theta) / f_{y}\left(20{ }^{\circ} \mathrm{C}\right)$. The $50 \%$ fractile corresponds to the nominal reduction factor as mentioned in EN 1992-1-2 [1]. In the bending moment calculations, the actual strength fractile of the concrete and the reinforcement is found by a randomly generated coefficient between 0 and 1 . In this way, the scatter of the mechanical properties as modeled by the normal distribution is taken into account.

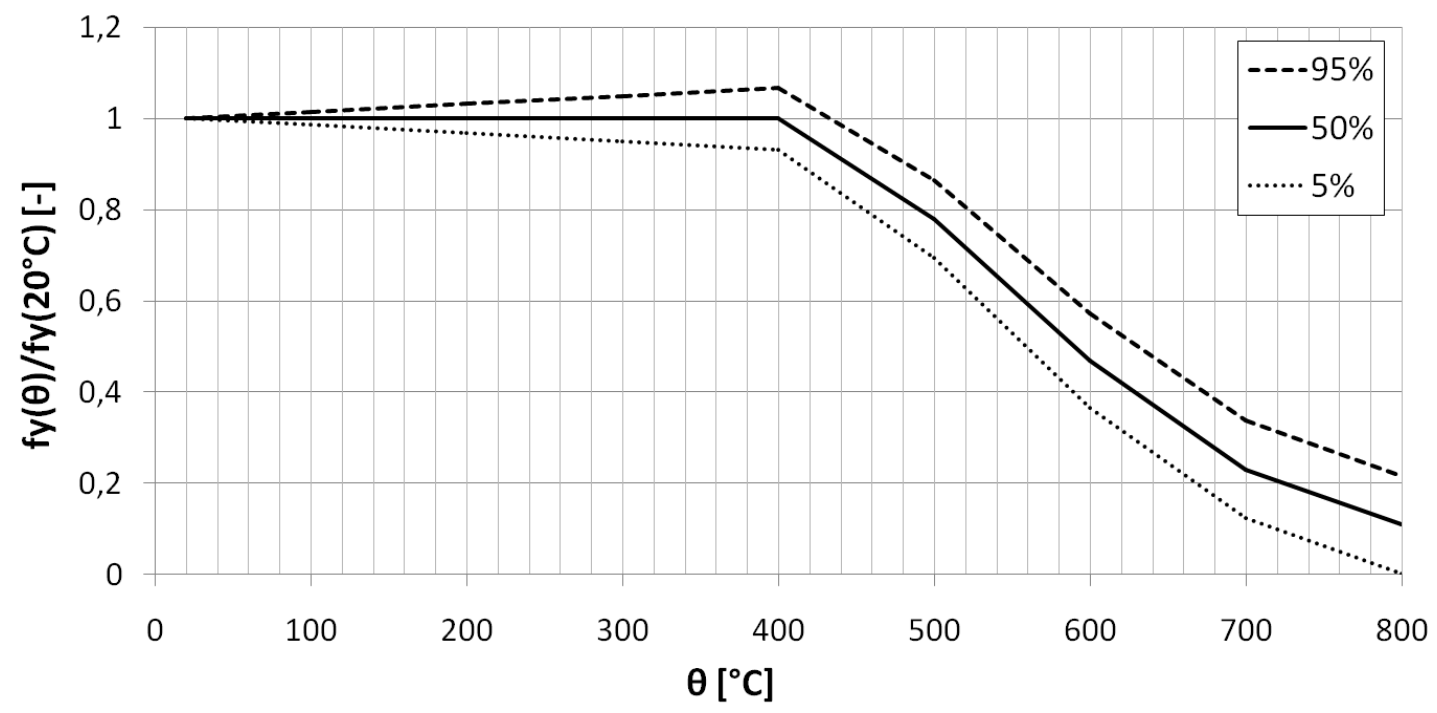

Fig. 3. Implemented random (stochastic) temperature effect on $f_{y}$.

Each slab or beam is characterized by a vector $\underline{X}$ of randomly generated values of the probabilistic parameters of Table 1 . By generating many variable vectors $\underline{X}$, calculating $M_{R, f i t}$ for each $\underline{X}$, and analyzing the results statistically, the evolution and corresponding uncertainty of $M_{R, f i t}$ during fire is calculated. This type of analysis by repeated random sampling of the parameter space is generally referred to as Monte Carlo sampling [6]. In this study a sample size of 10,000 slabs proves to be sufficient for an accurate calculation.

No spalling is taken into account, although this can be easily implemented through a probabilistic degradation function for the concrete cover $c$.

\section{Level of Safety Through Comparison with Design Values According to the Eurocode}

Based on EN 1992-1-2 [1], the specified fire resistance time can be calculated through Eq. 1, with $M_{R d, f, t}$ the design value of the bending moment capacity during fire at time $t$, and $M_{E d, f, t}$ the design value of the moment induced by the design loads. In accordance with the Eurocode, all the partial safety factors used for the calculation of theses design values are equal to 1 .

$M_{R d, f i, t} \geq M_{E d, f i, t}$

Equation 1 defines the fire resistance time as the time for which $M_{R d, f, t}$ is larger than $M_{E d, f, t}$. Based on EN 1992-1-2 [1], $M_{E d, f, t}$ can be further simplified to $M_{E d, f .}$. In this paper a variable design load of $7.5 \mathrm{kN} / \mathrm{m}^{2}$ is assumed, corresponding to the modeling of a slab used in a warehouse [7]. Further the dead weight of the slab is also taken into account and for the combination factor for the variable load a value $\psi=0.9$ is considered (for a warehouse).

In the developed model, a statistical analysis of this criterion is possible, as described by Eq. 2. This statistical analysis is performed by exchanging the design value $M_{R d, f, t}$ by the 'actual' bending moment capacity $M_{R, f i t,}$, which is described by 10,000 Monte Carlo simulations. This analysis results in $P_{f}$, the 
theoretical probability of failure. This is the probability of $M_{E d, f i}$ exceeding $M_{R, f i t}$ and is thus a measure for the theoretical probability of structural collapse at time $t$, thus indicating the achieved fire resistance time.

$$
P_{f}=P\left[M_{R, f i, t}<M_{E d, f i}\right]=\Phi\left(-\beta_{1}\right)
$$

Based on the frequentist interpretation of the concept probability [8], it is possible to evaluate Eq. 2 by counting the number of Monte Carlo simulations with $M_{R, f i t}$ smaller then $M_{E d, f i}$. However, in order to achieve a minimum degree of accuracy one would need to increase the number of Monte Carlo simulations considerably, exceeding practical calculation times. This problem is overcome by approximating the simulations of $M_{R, f i t}$ by a normal distribution with mean and standard deviation equal to the mean and standard deviation of the 10,000 Monte Carlo simulations.

Equation 2 introduces an alternative definition of a reliability index $\beta_{1}$, which considers only the stochastic nature of the resistance effect. The evolution of $\beta_{l}$ evaluated by Eq. 2 gives an indication of the increasing probability of bending moment failure. Though Eq. 2 is not the conventional definition of $\beta$, it can still be used to compare the safety level of different structures. The reliability index should however not be confused with a prediction of actual failure frequencies [7].

The safety level indicated by Eq. 2 depends on the applied load. Further, it is also interesting to analyze the probability of $M_{R d, f i t}$ overestimating the actual bending moment capacity $M_{R, f i, t}$ of the slab as this indicates which fractile of the bending moment distribution corresponds to the design value given by the Eurocodes. This fractile is approximately constant when the reduction factors for material strength are considered deterministic as indicated in the Eurocodes (leading to a constant $\beta_{2}$ value). However, in case the uncertainty with respect to the reduction factors is taken into account, this fractile is no longer constant (leading to a changing $\beta_{2}$ value).

$$
P_{f}=P\left[M_{R, f i, t}<M_{R d, f i, t}\right]=\Phi\left(-\alpha_{R} \beta_{2}\right)=\Phi\left(-\beta_{2}\right)
$$

In accordance with Ref. [7], the influence factor $\alpha_{R}$ can be assumed equal to 1. Equation 3 has the advantage that the evolution of the safety level of the concrete slab during fire is evaluated based solely on the intrinsic properties of the slab under consideration.

The problem of accuracy discussed for Eq. 2 is of less concern for Eq. 3. The number of results with $M_{R, f i, t}$ lower than $M_{R d, f i, t}$ proves to be large enough to calculate the probability without having to adopt an approximate normal distribution.

\section{SIMPLY SUPPORTED SLABS}

\section{Introduction of the Reference Slab Configuration}

Table 2 describes the configuration of the reference slab. According to the design approaches of EN 19921-2 [1], this slab configuration has a fire resistance of $240 \mathrm{~min}$. The probabilistic characteristics of the variables are indicated in Table 3. These values are derived from Ref. [5] and laboratory tests, the nominal value of $E_{c}\left(20^{\circ} \mathrm{C}\right)$ is evaluated through Eq. 4, as prescribed in Ref. [9]. For the reference slab a realistic uncertainty of $\pm 2 \mathrm{~mm}$ with respect to the concrete cover is taken into account.

$$
E_{c}(20)=E_{c m}=9.5\left(f_{c k}+8\right)^{1 / 3}
$$


Table 2. Configuration of the reference slab.

\begin{tabular}{|l|l|l|r|}
\hline \multicolumn{1}{|c|}{ Symbol } & \multicolumn{1}{c|}{ Name } & Dimension & Nominal value \\
\hline$l_{x}$ & slab width & $\mathrm{m}$ & 5 \\
\hline$l_{y}$ & slab length & $\mathrm{m}$ & 6 \\
\hline$h$ & thickness / height slab & $\mathrm{mm}$ & 400 \\
\hline$f_{c k}\left(20^{\circ} \mathrm{C}\right)$ & $20^{\circ} \mathrm{C}$ characteristic concrete compressive strength & $\mathrm{MPa}$ & 20 \\
\hline$f_{\mathrm{k} k}\left(20^{\circ} \mathrm{C}\right)$ & $20^{\circ} \mathrm{C}$ characteristic steel yield strength & $\mathrm{MPa}$ & 500 \\
\hline$E_{c}\left(20^{\circ} \mathrm{C}\right)$ & $20^{\circ} \mathrm{C}$ concrete modulus of elasticity & $\mathrm{GPa}$ & 28.848 \\
\hline$E_{s}\left(20^{\circ} \mathrm{C}\right)$ & $20^{\circ} \mathrm{C}$ steel modulus of elasticity & $\mathrm{GPa}$ & 200 \\
\hline$c_{\text {nominal }, 1}$ & concrete cover bottom & $\mathrm{mm}$ & 35 \\
\hline$\emptyset_{1}$ & bottom reinforcement diameter & $\mathrm{mm}$ & 10 \\
\hline$s_{1}$ & bar spacing bottom reinforcement & $\mathrm{mm}$ & 100 \\
\hline$c_{\text {nominal }, 2}$ & concrete cover top & $\mathrm{mm}$ & 35 \\
\hline$\emptyset_{2}$ & top reinforcement diameter & $\mathrm{mm}$ & 10 \\
\hline$s_{2}$ & bar spacing top reinforcement & $\mathrm{mm}$ & 100 \\
\hline$q$ & variable load & $\mathrm{kN} / \mathrm{m}^{2}$ & 7.5 \\
\hline
\end{tabular}

Table 3. Probabilistic variables for the reference slab.

\begin{tabular}{|l|r|r|l|}
\hline \multicolumn{1}{|c|}{ Symbol } & $\boldsymbol{\mu}$ & $\boldsymbol{\sigma}$ & Dimension \\
\hline$h$ & 400 & 5 & $\mathrm{~mm}$ \\
\hline$f_{c}\left(20^{\circ} \mathrm{C}\right)$ & 25.4 & 2.7 & $\mathrm{MPa}$ \\
\hline$f_{\mathrm{v}}\left(20^{\circ} \mathrm{C}\right)$ & 581.395 & 40.698 & $\mathrm{MPa}$ \\
\hline$E_{c}\left(20^{\circ} \mathrm{C}\right)$ & 28.848 & 4.327 & $\mathrm{GPa}$ \\
\hline$A_{s}$ & 801 & 16 & $\mathrm{~mm}^{2}$ \\
\hline$c$ & 35 & 2 & $\mathrm{~mm}$ \\
\hline$\chi$ & 1.2 & 0.15 & - \\
\hline
\end{tabular}

\section{Probabilistic Evaluation of the Reference Slab}

Introduction: Effects of Deterministic Fire on a 'Stochastic' Slab

First, the uncertainties with respect to the temperature effects are neglected. All variables from Tables 2 and 3 are implemented, with the exception of the concrete cover which is implemented deterministically, and the temperature effects on the mechanical properties of the concrete and the reinforcement, which are implemented according to the nominal reduction factors as given in EN 1992-1-2. Consequently, this first analysis is an application of the deterministic fire effects of EN 1992-1-2 [1] on a 'stochastic' slab.

Figure 4 illustrates the results for $M_{R, f, t}, M_{R d, f, t}$ and $M_{E d, f i}$. The uncertainty regarding $M_{R, f, t}$ is visualized by displaying the $5 \%, 50 \%$, and $95 \%$ fractiles. The simulation results are depicted as a percentage of $M_{R, f i, 0 \min , 50}$, being the $50 \%$ fractile of $M_{R, f i, t}$ at the start of the fire (i.e. at ambient temperature) with a value of $189.5 \mathrm{kN} \cdot \mathrm{m}$. 


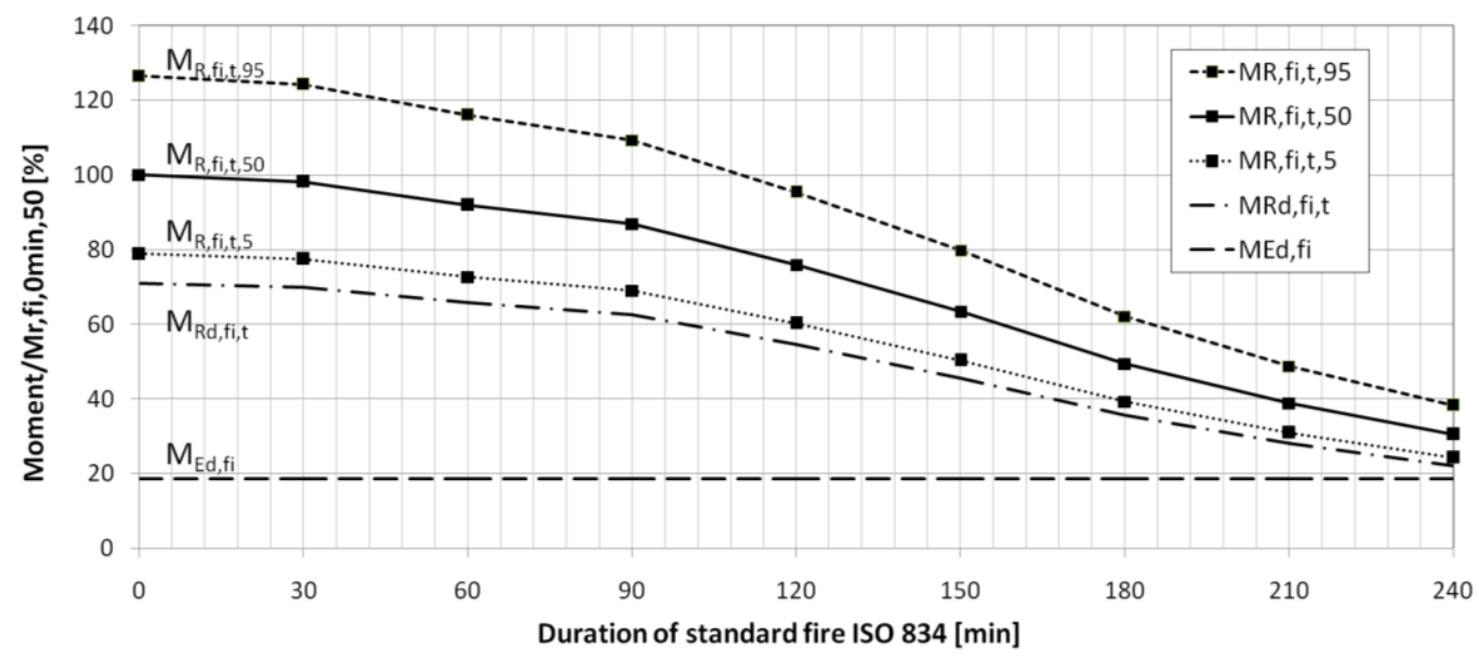

Fig. 4. Evolution of $M_{R, f i, t}$ for deterministic fire effects on reference slab $\left(M_{R, f, 0 \min , 50}=189.5 \mathrm{kN} \cdot \mathrm{m}\right)$.

Considering Eq. 1, Fig. 4 confirms a fire resistance time of about 240 min. From Fig. 4, it is clear that the bending moment capacity of the reference slab decreases strongly, especially after about 90 min of fire exposure. Since the fire effects are deterministic, it is to be expected that the coefficient of variation $\delta_{M R, f, t}$ remains unaffected (with a value of 0.14) during fire, which corresponds to a decrease in standard deviation $\sigma_{M R, f i t}$ in the graph, due to fact that the mean value $\mu_{M R, f, t}$ decreases. The above results are translated into the safety indices $\beta_{1}$ and $\beta_{2}$ in Fig. 5.

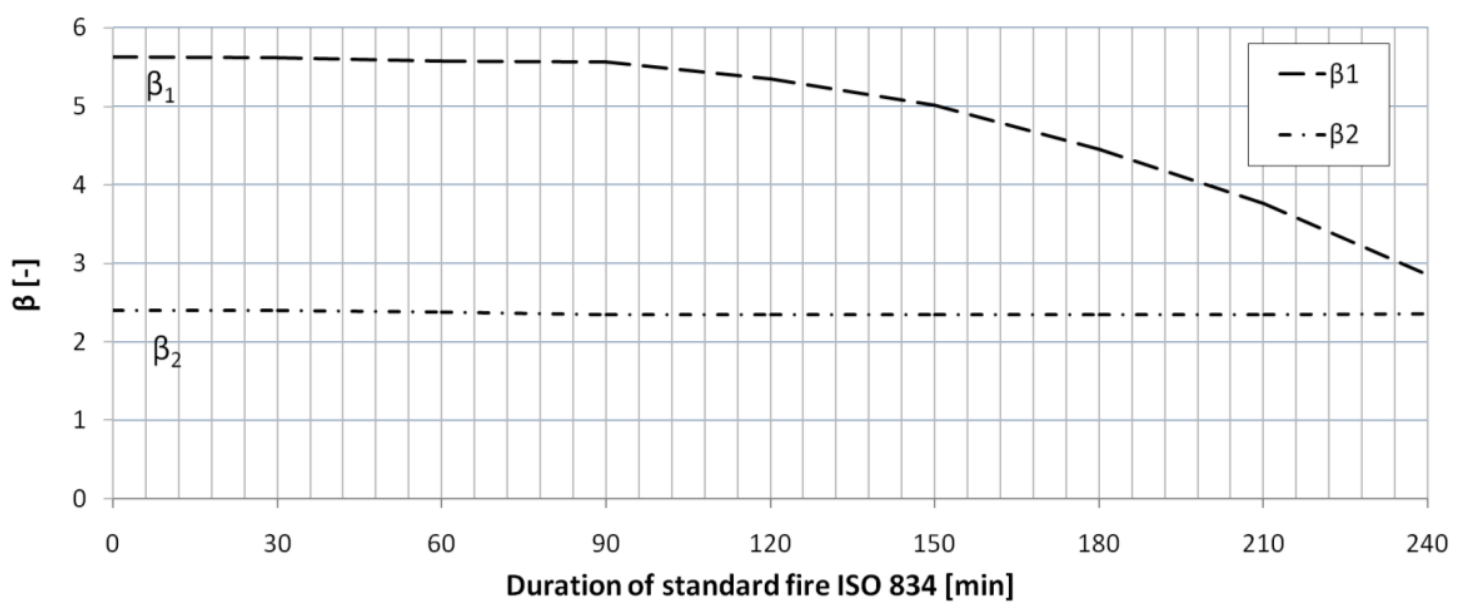

Fig. 5. Evolution of $\beta_{1}$ and $\beta_{2}$ for reference slab.

Figure 5 shows that for this simulation the safety on the resistance side, $\beta_{2}$, remains nearly constant during the entire fire. This is to be expected since no uncertainties regarding the fire effects on the slab are taken into consideration. The safety index $\beta_{1}$ however is nearly constant for the first $90 \mathrm{~min}$, but strongly decreases after $150 \mathrm{~min}$ of exposure to the ISO 834 fire.

Combining Eqs. 1 to 3, it is clear that Eqs. 2 and 3 are identical at the fire resistance time, resulting in the notion that mathematically the fire resistance time of the slab is reached when $\beta_{2}$ and $\beta_{1}$ intersect. In Fig. 5 there remains a gap between both curves, even at the tabulated fire resistance time of $240 \mathrm{~min}$. Firstly, this is a consequence of $\beta_{1}$ being evaluated through the approximation of the distribution for $M_{R, f i t}$ (considered as a normal distribution), while $\beta_{2}$ is evaluated based upon a frequentist approach. Secondly, an extrapolation of both curves results in an intersection at $256 \mathrm{~min}$, while similarly the intersection of $M_{R d, f, t}$ and $M_{E d, f i}$ in Fig. 4 results in a fire resistance time of approximately $258 \mathrm{~min}$. This correspondence validates the used methodology. 
One can conclude that the tabulated fire resistance from EN 1992-1-2 [1] is confirmed to be slightly conservative. However, the total safety level of the slab $\left(\beta_{l}\right)$ reduces quickly after $150 \mathrm{~min}$, corresponding to a fast increase of the probability of structural failure. This indicates that the fire resistance time calculated in accordance with the Eurocode should be strictly interpreted, i.e. the probability of failure rapidly increases to unsafe levels once the fire resistance time is reached.

Based on the previous investigation, the tabulated fire resistance time of 240 min corresponds to a limit value for $\beta_{1}$ of approximately 2.85 .

\section{Full-Probabilistic Evaluation}

Additional uncertainties should be taken into account when developing a full-probabilistic model to assess the effect of fire on structural elements. Firstly, the reinforcement temperature is uncertain due to small variations of the concrete cover. Secondly, with increasing temperature, the relative uncertainty with respect to the steel yield strength and the concrete compressive strength increases. This effect is evaluated as described in the section on the initial deterministic approach which introduces an uncertainty with respect to the strength reduction factors mentioned in EN 1992-1-2 [1] for mechanical properties at elevated temperatures. Both effects are referred to as 'fire effects' further in the text.

Figure 6 shows the results for the reference slab found with the full-probabilistic approach. In this graph $100 \%$ corresponds with $189.6 \mathrm{kN} \cdot \mathrm{m}$. As expected, this value is almost identical to $M_{R, f, 0 \mathrm{~min}, 50}$ in the previous simulation (Fig. 4).

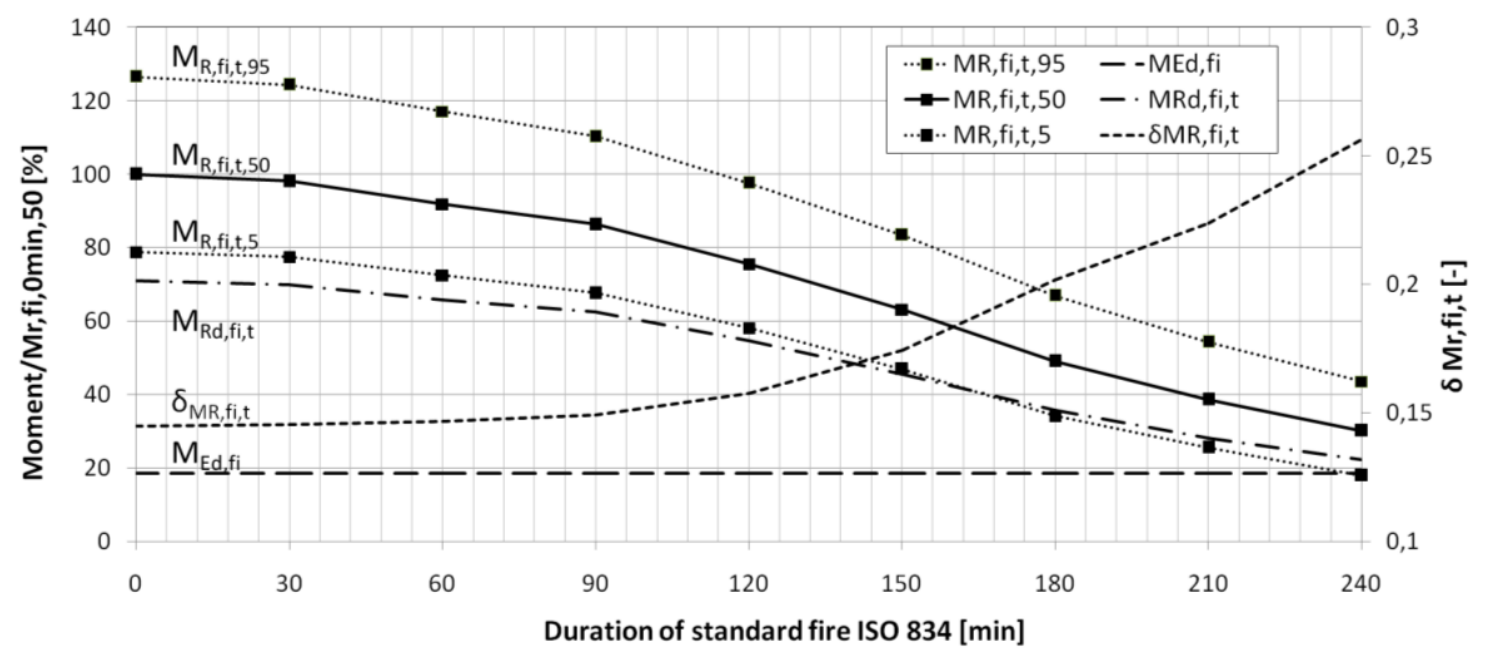

Fig. 6. Evolution of $M_{R, f i, t}, M_{R d, f i t}$ and $M_{E d, f i}$ for full-probabilistic reference slab $\left(M_{R, f i, 0 \mathrm{~min}, 50}=189.6 \mathrm{kN} \cdot \mathrm{m}\right)$.

Inclusion of the uncertainty with respect to the material strength reduction results in $M_{R, f i, t, 5} \operatorname{crossing} M_{R d, f, t}$ at approximately $165 \mathrm{~min}$. Furthermore, these stochastic effects result in an increase of $\delta_{M R, f, t}$ during fire from 0.14 at 0 min to 0.26 at $240 \mathrm{~min}$ of exposure.

For this full-probabilistic simulation $\beta_{1}$ corresponding with the tabulated fire resistance time of $240 \mathrm{~min}$ is reduced to 1.50 .

Comparing the results with deterministic fire effects (DET) to the full-probabilistic results (PROB) in Fig. 7 and Fig. 8, it is clear that including the uncertainty of fire effects on the mechanical properties and the (indirect) uncertainty of the steel temperature is crucial when analyzing the structural safety of a concrete slab during fire. 


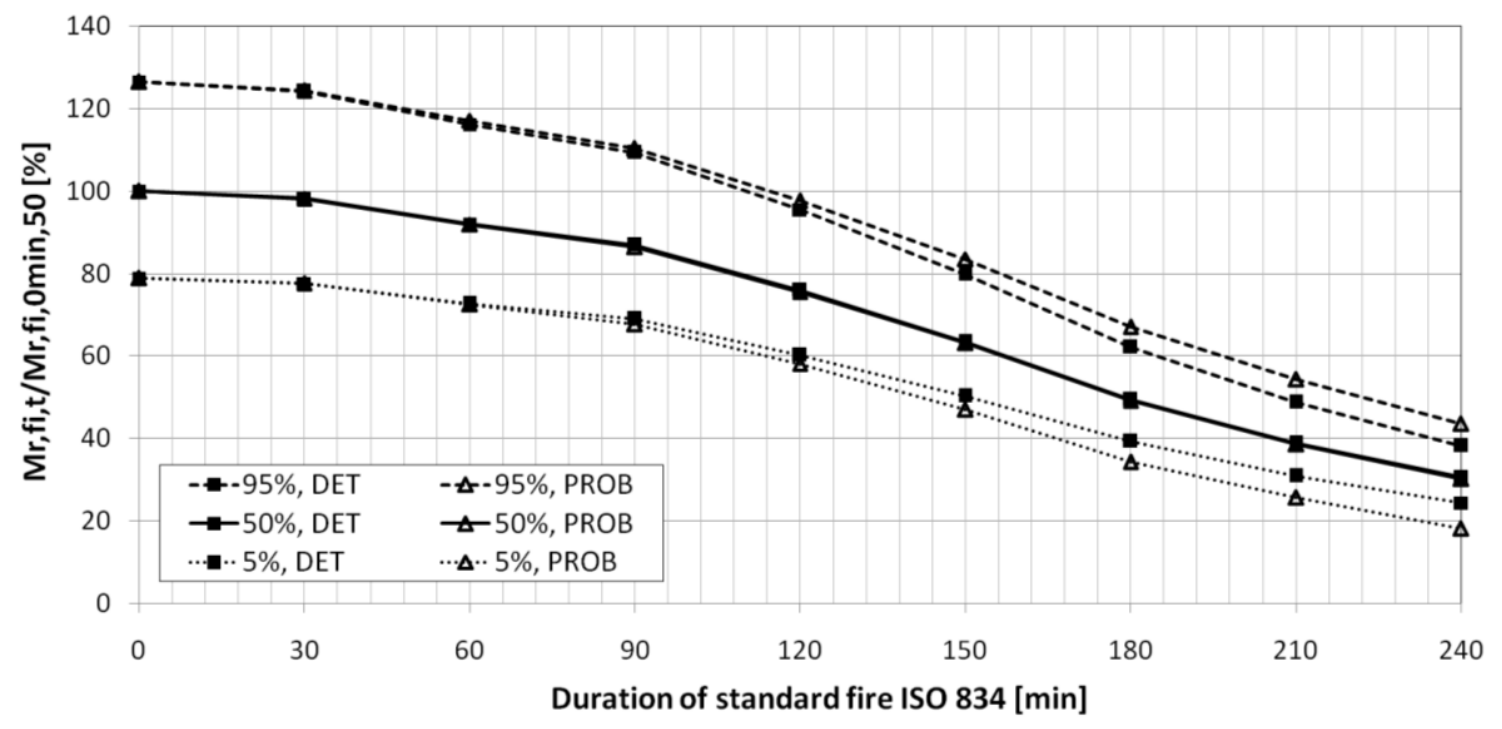

Fig. 7. Comparison of $M_{R, f i t}$ : deterministic fire effects (DET) vs. probabilistic fire effect (PROB).

While no significant difference is found for the evolution of $M_{R, f, t, 50}$, a further reduction of $M_{R, f, i, 5}$ and an increase of $M_{R, f i, t, 95}$ is found when incorporating the additional uncertainty of the fire effects. This results in larger values for $\sigma_{M R, f i t}$ and lower values of the safety indices $\beta_{I}$ and $\beta_{2}$ (see Fig. 8).

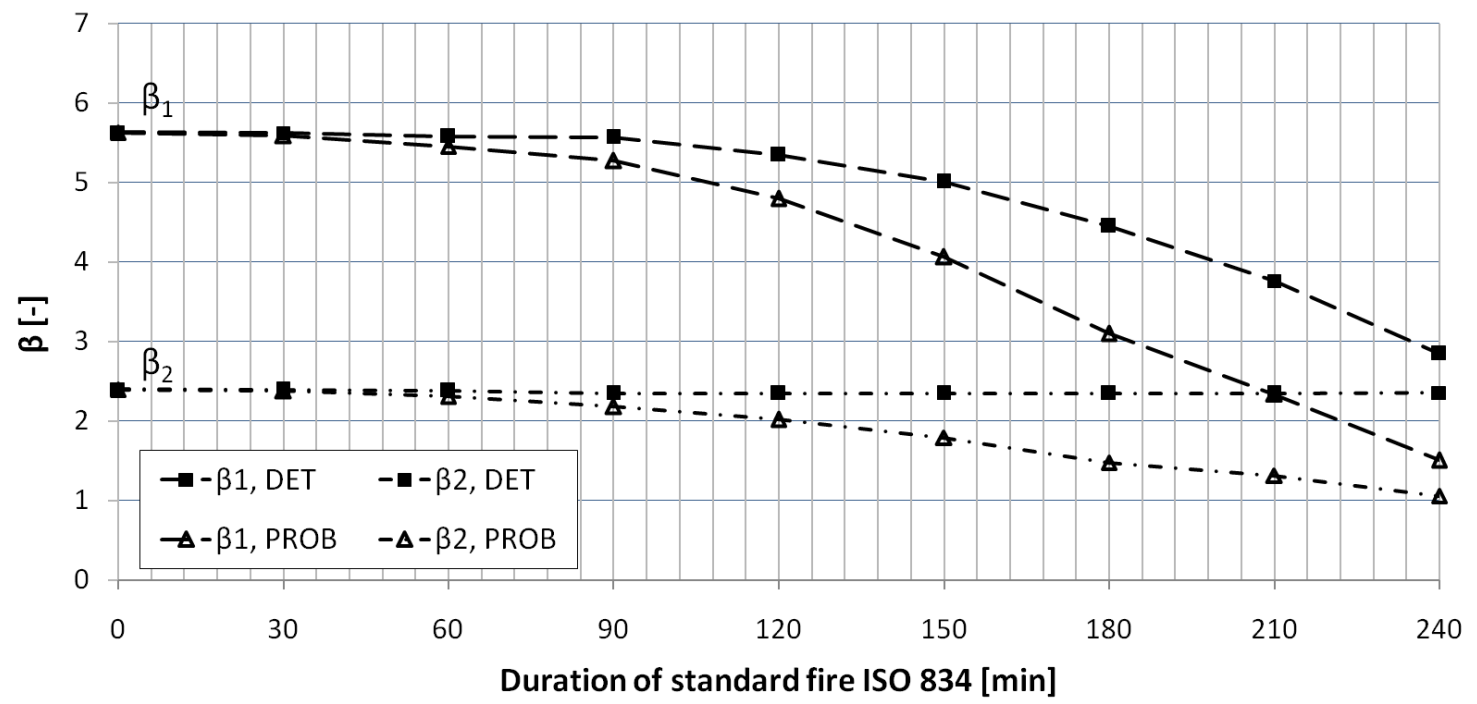

Fig. 8. Comparison of $\beta$ : deterministic fire effects (DET) vs. probabilistic fire effect (PROB).

The calculations show that it is important to include the uncertainty of fire effects in order to correctly evaluate the safety level of the concrete slab. Further investigation with respect to the correct modeling of this fire effect uncertainty is necessary in order to produce more accurate results. However, the difference in fire resistance time predicted by the intersection of $\beta_{1}$ and $\beta_{2}$ is minimal. The DET-curves intersect at $256 \mathrm{~min}$ and the PROB-curves at $263 \mathrm{~min}$.

\section{Study of the Concrete Cover and Definition of a Limit Value for $\beta$}

In case no parameter study of the influence of the steel diameter $\varnothing$ is executed, EN 1992-1-2 [1] provides values for the specified fire resistance time for simply supported solid slabs as a function of the concrete cover $c$. Assuming the design approaches of EN 1992-1-2 [1] to be conservative, an assessment of a generalized target value for the safety index can be made. This analysis is performed by calculating the $\beta_{1}$ 
values of alternative slab configurations for which only the nominal concrete cover is changed. These simulations are performed with the full-probabilistic model.

Table 4 presents the investigated concrete covers, the corresponding fire resistance $R$ according to Ref. [1], and the $\beta_{1}$ and $\beta_{2}$ results for these fire resistance times obtained by Monte Carlo simulations.

Table 4. Overview of concrete covers, corresponding tabulated fire resistance and calculated $\beta_{1}$ and $\beta_{2}$.

\begin{tabular}{|c|c|c|c|}
\hline $\boldsymbol{c}(\mathbf{m m})$ & $\boldsymbol{R}(\mathbf{m i n})$ & $\boldsymbol{\beta}_{\boldsymbol{1}}$ & $\boldsymbol{\beta}_{\boldsymbol{2}}$ \\
\hline 5 & 60 & 0.89 & 0.87 \\
\hline 10 & 90 & 0.70 & 0.84 \\
\hline 15 & 120 & 0.73 & 0.89 \\
\hline 25 & 180 & 1.02 & 0.98 \\
\hline 35 & 240 & 1.50 & 1.06 \\
\hline
\end{tabular}

Analyzing the test results of Table 4, the safety level appears to increase with increasing concrete cover. This indicates that the tabulated values for large fire resistance times correspond to a larger relative safety margin.

Comparison of the tabulated fire resistance times of EN 1992-1-2 [1] with the full-probabilistic simulation results for $\beta_{1}$ shows that a $\beta_{1}$ value of 1 approximately corresponds to the achieved fire resistance time. This limit value is however assessed by assuming no scatter around $M_{E d, f i}$ and a normal distribution of $M_{R, f i, t}$, which can be avoided through the frequentist evaluation of $\beta_{2}$, since $\beta_{1}$ and $\beta_{2}$ should be identical at the fire resistance time due to the correspondence of Eq. 2 and Eq. 3.

\section{CONCLUSIONS}

- A full-probabilistic model is developed for analyzing the safety level of concrete slabs.

- The design approaches of EN 1992-1-2 for simply supported solid slabs correspond to a higher safety level for larger fire resistance times.

- The design approaches of EN 1992-1-2 correspond to a full-probabilistic safety index of approximately 1 at the specified fire resistance time.

- Further research on the uncertainty of the fire effects on material properties is necessary.

\section{REFERENCES}

[1] EN 1992-1-2, Design of concrete structures: Structural fire design, European Standard, CEN, 2004.

[2] EN 1991-1-2, Actions on structures: Actions on structures exposed to fire, European Standard, CEN, 2002.

[3] Fletcher, I.A., Welch, S., Torero, J.L., Carvel, R.O., and Usmani, A., (2007) The behavior of concrete structures in fire, Thermal Science 11(2) 2: 37-52, http://dx.doi.org/10.2298/TSCI0702037F

[4] EN 1992-1-2, Design of concrete structures: General rules and rules for buildings, CEN, 2004.

[5] Holický, M. and Sýkora, M., "Stochastic models in analysis of structural reliability", Proceedings of the International Symposium on Stochastic Models in Reliability Engineering, Life Sciences and Operation Management, 2010.

[6] Ang, A.H.-S. and Tang, W.H., Probability concepts in engineering ( $2^{\text {nd }}$ ed.). John Wiley \& Sons, New York, 2007.

[7] EN 1990, Basis of structural design, European Standard, CEN, 2002.

[8] Walpole, R.E., Myers, R.H., Myers, S.L. and Ye, K., Probability \& Statistics for Engineers \& Scientists $\left(8^{\text {th }}\right.$ ed.), Pearson Education International, London, 2007.

[9] Belgian Concrete Group (BBG), Concrete Technology (in Dutch), Brussels, 2006. 